\title{
Analysis of the Relationship between Social Phobia and Creative Thinking and Problem Solving of the Teenage Girls
}

\author{
Azar Farhadi Afshar ${ }^{1 *}$
}

\section{ABSTRACT}

Social anxiety is one of the common problems of the students. This study aimed to investigate the relationship between social phobia and creative thinking and problem solving of the teenage girls in a sample of the students in Sirjan city. This is a relationship research. To this end, 250 male and female students were selected through cluster random sampling. For data collection, Creativity Test (CT), problem solving methods questionnaire, and social phobia inventory were used that had acceptable reliability and validity. For statistical analysis, the mean and standard deviation were used for descriptive statistics and Pearson correlation and multiple regressions were used for inferential statistics. The results showed that all styles of problem solving and creativity R2=0.17 explain the variance of the social anxiety. Accordingly, it can be concluded that problem solving styles and creativity are can significantly explain social anxiety of the students.

\section{Keywords: Social Anxiety, Creative Thinking, Problem Solving}

Social anxiety is characterized by a continuous and evident fear of one or more social situations so that patients feel that their actions and behaviors are judged and therefore, avoid the interpersonal and social relationships. Social anxiety is also associated with some physiological, psychological and behavioral traits (Wells, 2004). Creative thinking is one of the variables that can interact with the psychological traits of the students including high or low social anxiety and affect their academic progress. Therefore, investigating the relationship between this variable and social anxiety of the students can show the factor affecting the academic and social progress of the students. Creative thinking is a kind of thinking that result in new insights, approaches, perspectives and new ways to understand the objects and situations (Burker \& Stephens, 1999).

On the other hand, social anxiety can be due to a false and inflexible view toward the society and its people. Students with high social anxiety may avoid a broad range of the social situations,

\footnotetext{
${ }^{1}$ MA of Clinical Psychology, Department of Psychology Sirjan Branch, Islamic Azad University, Sirjan, Iran *Responding Author

Received: January 12, 2017; Revision Received: February 9, 2017; Accepted: February 15, 2017

(C) 2017 Afshar A; licensee IJIP. This is an Open Access Research distributed under the terms of the Creative Commons Attribution License (www.creativecommons.org/licenses/by/2.0), which permits unrestricted use, distribution, and reproduction in any Medium, provided the original work is properly cited.
} 


\section{Analysis of the Relationship between Social Phobia and Creative Thinking and Problem Solving of the Teenage Girls}

escape these situations after a short time, or may appeal to some security behaviors such as wearing the turtleneck sweater with high collar to hide their shame, avoid eye contact in social situations and ask questions of other people to avoid talking about themselves. It seems that creative people tend to expose themselves to criticism and evaluation, and experience other image of the world around them. Passer et al (2009) suggested the use of creative thinking techniques can reduce anxiety. They believed that creative thinking is a kind of skill that produces exploratory force and new attitude that results in changing the negative feelings into positive ones and is effective in improving the health while unpleasant things occur.

Problem solving skill or behavior is another research variable that investigating its relationship with high or low social anxiety is helpful. Problem solving is a cognitive behavioral process that helps people to find or innovate the efficient or coping with strategies for daily problems. Problem solving is a kind of effort for finding a solution that should be successfully and consecutively carried out by a series of stages and the solution should be sought (D'Zurilla \& Nezu, 2010).

Finding the solution requires a range of cognitive skills, including interpretation of data, planning, and methodological memory, controlling the results and seeking to change outcomes (Zare \& Baradaran, 2014). It seems that teenage students' notably female students that experience high social anxiety are not able to interpret the difficulties in social situations and suffer from high anxiety due to the lack of concentration on logical solutions for successful presence in society, among friends, relatives, classroom and so on. It may be said that anxious students in social context show the anxiety symptoms because they have no true definition of the social problems that make them anxious. They have no certain reflection on the effect and consequences of the stressful and social problems and events and take no coping strategies for overcoming the complex situations, but having the problem solving skill, coping and practical strategies is useful in reducing anxiety and increasing the self- confidence and better compatibility.

Since no study has been conducted of this kind, this study can be considered as a basic research on the etymology of the social anxiety of the female teenage students. Although literature has shown that high social anxiety usually begins during childhood and adolescence, but little studies has addressed adolescents in Iran. Moreover the severity of the social anxiety of the children and adolescents is related to the academic avoidance and is associated with main problems in their performance. Therefore, this study aimed to explore is there any significant relationship between the creative thinking and problem solving and social anxiety of the female students of the first grade of high school in Sirjan? 


\section{Analysis of the Relationship between Social Phobia and Creative Thinking and Problem Solving of the Teenage Girls}

\section{METHOD}

This study is a descriptive - correlational study in terms of nature and purpose, because it investigates relationship between the three variables. The statistical population consisted of all high school first grade students in Sirjan. Due to correlational nature of the study, 250 high school first grade students were selected by random cluster sampling based on Cochran formula. To this end, at first the license for presence and administration of the research in schools was taken from Education Department of Sirjan and five schools were randomly selected from north, south, east, west and center of Sirjan. Then, three classes $-7^{\text {th }}, 8^{\text {th }}, 9^{\text {th }}-$ were randomly selected. After coordination with school managers and teachers, 300 questionnaires were distributed among the students. 250 questionnaires were completely filled and were collected for statistical analysis.

\section{Research instruments}

1. Abedi creativity test (CT): Abedi creativity test is a three option test that its original form contained 50 questions. Its 70 items form was introduced in 1996 by O'Neill et al and in 1996, its 60 items form was developed that contains four dimensions (fluency, elaboration, flexibility and initiative). The answers are scored using three options that show low, medium and high creativity. The sum of these scores, indicates total score of person's creative thinking. Zarei et al (2001) obtained reliability of this questionnaire by Cronbach's alpha for the total test as 0.88 . Correlational coefficients of validity is from 0.15 to 0.41 among four scores of Torrance's creativity and four test score of Abedi's creativity. The highest correlations were obtained between the verbal narrative scores. In addition, its correlation with teachers' ratings of students has been calculated. There were meaningful correlations between sub-criteria of Abedi creativity test and academic achievement criteria and scores of Torrance creativity test and creativity and Villa and Auzmendi creativity test. These coefficients were reported on average and higher than the average and all were significant at higher level of $\mathrm{P}<0.01$. Abedi creativity test reliability is from 0.61-0.75 in its four subscales Cronbach's coefficients of internal consistency (Ahmadi, 2005).

2. Problem Solving Style Inventory: problem solving scale was developed by Cassidy and Lang (1996) in two phases and has 24 questions which measure six factors, each of which contains four items in test. These factors include: failure, control, problem solving, creativity style, confidence in problem-solving, avoiding style, and orientation style. Questions are scored using a three-point scale: "Yes (score: 1), No (score: 0), and I do not know (score: 0.5 )". The sum of these scores represents an overall score for each of the six factors. So, each factor having four questions, is scored with a minimum of zero and a maximum of eight. Each factor that has the highest scores, indicates that person when facing daily problems use it to solve the problem. Problem solving style scale were validated by Muhammadi and Sahebi (quoted from Baraheni, 1994) and alpha 
coefficients were confirmed. Since alpha coefficients are above 0.50 and alpha mean is 0.60 , and since internal correlation of text items, this scale has acceptable validity.internal validity of this scale was obtained by Shakeri et al (2014) using alpha coefficient as 0.77.

3. Social Phobia Scale: This scale was developed to measure anxiety in interpersonal interactions which contains 17 items that are scored on five point Likert scale from Notat all too Very high. This questionnaire has high validity and reliability. In this scale, high score indicates interactive social anxiety of the subject. Moreover, its validity was 0.78 to 0.89 using retest in groups with a diagnosis of social phobia abnormality and coefficient of internal consistency (Cronbach's alpha) in a normal group was reported as 0.94. Furthermore, it was reported as 0.89 for subscale of fear, 0.91 for avoidance, and 0.80 for psychological distress. Construct validity was investigated compared to the results of this test in two groups of subjects by diagnosis of social phobia abnormality and subjects of the normal group with psychological diagnosis that showed a significant difference that indicates its high validity (Salajaghe \& Bakhshaeo, 2014).

\section{RESULTS}

Data collected by descriptive statistical methods such as mean, standard deviation, and inferential statistics included Pearson correlation coefficient and linear regression. The mean and standard deviation of the scores of the sample group were reported in variables in Table 1.

Table 1: Mean and standard deviation of the scores of the sample group in research variables

\begin{tabular}{|l|l|l|l|}
\hline Variable & Number & M & SD \\
\hline Helplessness & 250 & 4.24 & 2.74 \\
\hline Problem Solving control & 250 & 5.05 & 2.16 \\
\hline Creative Style & 250 & 3.6 & 1.89 \\
\hline Problem Solving Confidence & 250 & 4.7 & 2.02 \\
\hline Avoidance Style & 250 & 4.17 & 2.46 \\
\hline Approach Style & 250 & 5.24 & 2.78 \\
\hline General Problem Solving & 250 & 27.12 & 5.15 \\
\hline Problem Solving & 250 & 77.58 & 8.74 \\
\hline Social Anxiety & 250 & 45.14 & 9.2 \\
\hline
\end{tabular}

First hypothesis: There is a significant relationship between creative thinking and social anxiety of the middle school students in Sirjan. Table 2 shows the final result of analysis of variance to predict social anxiety through creative thinking.

Table 2: Final analysis of variance to predict social anxiety through creative thinking

\begin{tabular}{|l|l|l|l|l|l|}
\hline Source changes & Sum of squares & Df & Mean Square & F & Sig. \\
\hline Regression & 3385.11 & 1 & 3385.11 & \multirow{2}{*}{33.82} & \multirow{2}{*}{0.001} \\
\hline Residue & 24824.15 & 248 & 100.09 & & \\
\hline Total & 28209.26 & 249 & & & \\
\hline
\end{tabular}




\section{Analysis of the Relationship between Social Phobia and Creative Thinking and Problem Solving of the Teenage Girls}

As shown in table above and with regard to the obtained F (33.82) with degrees of freedom (1248) it can be said that creative thinking significantly predict social anxiety (0.01). Table 3 shows the standard and non-standard regression coefficients for creative thinking to predict social anxiety in the sample group.

Table 3: The standard and non-standard regression coefficients for creative thinking to predict social anxiety

\begin{tabular}{|l|l|l|l|l|l|l|}
\hline $\begin{array}{l}\text { criterion } \\
\text { variable }\end{array}$ & $\begin{array}{l}\text { Predictor } \\
\text { variables }\end{array}$ & $\mathbf{B}$ & $\begin{array}{l}\text { standard } \\
\text { error }\end{array}$ & $\boldsymbol{\beta}$ coefficient & t & Sig. \\
\hline- & Invariant measure & 68.71 & 6.96 & & 9.87 & 0.01 \\
\hline 1 & Creative Thinking & 0.27 & 0.077 & 0.34 & 3.47 & 0.01 \\
\hline indicator & $\mathrm{R}$ & \multicolumn{2}{|c|}{$\mathrm{R}^{2}$} & SE \\
\hline measure & 0.34 & 0.12 & 7.58 & \\
\hline
\end{tabular}

With respect to multivariate regression coefficients, it can be said that in the regression model, creative thinking with standard regression coefficient (0.34) can predict social anxiety of the students. Analyzing the model showed that creative thinking $12 \%=\left(\mathrm{R}^{2} \times 100\right)$ explain social anxiety variance.

The second hypothesis: there is a significant relationship between the problems solving with social anxiety of the middle school students in Sirjan.

Table 4 shows final analysis of variance to predict social anxiety through problem-solving styles.

Table 4: final analysis of variance to predict social anxiety through problem-solving styles

\begin{tabular}{|l|l|l|l|l|l|}
\hline Source changes & Sum of squares & Df & Mean Square & F & Sig. \\
\hline regression & 4795.57 & 6 & 799.26 & 48.85 & $0 / 01$ \\
\hline residue & 23413.69 & 243 & 96.35 & & \\
\hline Total & 28209.26 & 249 & & & \\
\hline
\end{tabular}

According to the table above and according to the obtained $\mathrm{F}$ (48.85) with degrees of freedom (6 and 243) it can be said that problem-solving methods significantly (0.01) predict the students' social anxiety.

Table 5 standard and non-standard regression coefficients for problem-solving methods to predict social anxiety in the sample group. 
Analysis of the Relationship between Social Phobia and Creative Thinking and Problem Solving of the Teenage Girls

Table 5: standard and non-standard regression coefficients for problem-solving methods to predict social anxiety

According to multivariate regression coefficients, it can be said that in the regression model,

\begin{tabular}{|c|c|c|c|c|c|c|}
\hline $\begin{array}{l}\text { criterion } \\
\text { variable }\end{array}$ & Predictor variables & B & \begin{tabular}{|l|}
$\begin{array}{l}\text { standard } \\
\text { error }\end{array}$ \\
\end{tabular} & 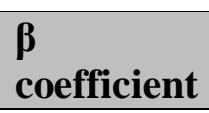 & $\mathbf{t}$ & Sig. \\
\hline \multirow{7}{*}{$\begin{array}{l}\text { social } \\
\text { anxiety }\end{array}$} & Invariant measure & 62.09 & & & 6.57 & 0.01 \\
\hline & helplessness & -0.33 & 0.076 & -0.38 & -4.25 & 0.01 \\
\hline & $\begin{array}{l}\text { problem solving } \\
\text { control }\end{array}$ & -0.067 & 0.019 & -0.208 & -3.515 & 0.001 \\
\hline & creative style & 0.087 & 0.037 & 0.287 & 2.297 & 0.023 \\
\hline & approach style & 0.152 & 0.047 & 0.36 & 3.220 & 0.002 \\
\hline & avoidance style & -0.134 & 0.026 & -0.297 & -4.976 & 0.01 \\
\hline & confidence & 0.021 & 0.041 & 0.063 & 0.510 & 0.611 \\
\hline indicator & \multicolumn{2}{|l|}{$\mathrm{R}$} & \multicolumn{2}{|c|}{$R^{2}$} & \multicolumn{2}{|l|}{$\mathrm{SE}$} \\
\hline Value & \multicolumn{2}{|l|}{0.41} & 0.17 & & \multicolumn{2}{|l|}{5.16} \\
\hline
\end{tabular}

Problem solving styles of failure with standardized regression coefficient $(-0.38)$, controlling style with regression coefficient (-0.208), creativity style with standardized regression coefficient (0.287), orientation style with a standardized regression coefficient (0.36) and avoiding style with a regression coefficient $(-0.297)$ can predict social anxiety of the students. The model analysis showed that a total of 17 problem solving and creativity styles predict $\left(\mathrm{R}^{2} \times 100\right)$ of social anxiety variance.

\section{DISCUSSION AND CONCLUSION}

This study aimed to investigate the relationship between social phobia and creative thinking and problem solving of the teenage girls in a sample of students in Sirjan city. Regression analysis showed that creative thinking significantly predicts social anxiety of the students. Also, according to multivariate regression coefficients, in the regression model, creative thinking with a standard regression coefficient (0.34) can predict social anxiety of the students. Model analysis showed that creative thinking explains a total of $12 \%$ of the variance in social anxiety. These results are consistent with those of Khayer and Ostovar (2007), Ranjdoost and Eivazi (2013), Soltani and Mikaeili (2012).

Results also showed that problem-solving methods significantly predict students' social anxiety. According to multivariate regression coefficients, in the regression model, problem solving styles of failure, control, avoidance with negative regression coefficients and style of creativity and orientation with positive and standard regression coefficient can predict social anxiety. The model analysis also showed that problem solving styles explain a total of $17 \%$ of the variance of social anxiety. These results are consistent with those of Babashahabi and Kashaninia (2007), Shaghaghi and RezaeiKaregar (2007), Dehghani et al (2013).

(C) The International Journal of Indian Psychology, ISSN 2348-5396 (e)| ISSN: 2349-3429 (p) | 48 


\section{Analysis of the Relationship between Social Phobia and Creative Thinking and Problem Solving of the Teenage Girls}

Ahernse (2009) investigated the problem solving ability of students with an academic position, reading, and the ability to understand and sex. This study reported important relationships between problem solving ability and academic achievement, problem solving ability and compression and also showed a significant difference between the problem solving ability of the male and female students; therefore, it can be concluded that academic achievement of the students and reading the scores is ability to understand and predict the problem solving ability that excludes sex (Chang, 1998).

Education plays a major role in academic and career achievement of the people, therefore educational planning can help people to choose the most appropriate major and job and achieve success. Therefore, analyzing the factors that have negative or positive impact on academic process of the students force the educational planners to act based on information. Due to the importance of education, many studies have been conducted on factors affecting this choice, including individual problem solving. People who are involved in education, know that students think and learn in different ways. For example, a student may be interested in doing regular homework, while the other hate it. One student may use new methods but the other may fear and avoid them. One student may do regular homework, while the other may not or do it insurgent. These differences are not due to their abilities but they occur due to the different styles or they may prefer to use their abilities in different ways. Therefore, styles are our orientation or preferences not our abilities (Sternberg, 2000). Although, primary perceptions and old theories consider creativity as the talent that belongs to some certain people, but history shows that main changes in the world has been made by a limited number of people who had creative problem solving styles and most of the innovations were made by these people. Due to the fact, many education experts argue that in today's changing world, creativity teaching and creativity for learners is one of the heaviest and most important goal of any educational system (Issazadeganet al., 2013). In our schools, teachers use traditional teaching methods based on the assumption that the person must first read and then think. Using the traditional and inflexible methods reduces creativity and increases anxiety of the students because they have no ability to face the new teaching and social situations. Students can have positive or negative presence in their academic process with respect to the extent to which their problem solving styles is consistent or inconsistent and experience higher or lower anxiety.

Research constraints include: lack of cooperation of some students to carry out and complete the questionnaires, the results of this study may be generalized for high school first grade students. The subjects' answers can be community-friendly not their real answer, hence caution in the interpretation of the results and the validity of the results should be considered. It is also recommended that the variables examined in this study can be used as a model in future research. In future studies, it is better to consider demographic variables in addition to the psychological 


\section{Analysis of the Relationship between Social Phobia and Creative Thinking and Problem Solving of the Teenage Girls}

and cognitive variables to explain and predict social anxiety. In future studies it is better that other standard tools are used for measuring variables such as creativity and problem solving.

\section{Acknowledgments}

The author appreciates all those who participated in the study and helped to facilitate the research process.

Conflict of Interests: The author declared no conflict of interests.

\section{REFERENCES}

Ahmadi, M. (2008). Standardization of the Torrance Test of Creative Thinking for high school students in Tehran, psychology master's thesis, Imam Khomeini International University.

Babashahabi, R., \& Kashaninia, Z. (2010). Survey the effect of problem solving skills on social anxiety in unsupervised adolescents living in boarding houses of Kurdistan welfare office. Scientific. Journal of Kurdistan University of Medical Sciences,12(43),18-25.

Burke, R. S., \& Stephens, R. S. (1999). Social anxiety and drinking in college students: A social cognitive theory analysis. Clinical psychology review, 19(5), 513-530.

Cassidy, T., \& Long, C. (1996). Problem-solving style, stress and psychological illness: Development of a multifactorial measure. British journal of clinical psychology, 35(2), 265-277.

Chang, E. C. (1998). Hope, problem-solving ability, and coping in a college student population: Some implications for theory and practice. Journal of clinical psychology, 54(7), 953-962.

D’Zurilla, T. J., \&Nezu, A. M. (2010). Problem-solving therapy. Handbook of cognitivebehavioral therapies, 3, 197-225.

Dehghani, Y., \&Dehghani, M. (2013). Relationship among creatively, job satisfaction and mental health in female nurses. Iran Journal of nursing, 26(81), 32-43.

Isazadegan, A., Mikaili, F., Husseinjenaabadi, M., \& Qulinezhad, F. (2014). Comparison thinking styles and emotional creativity among gifted and normal students. Journal of Exceptional Children, 3(11), 107-126.

Mikaili, F., \&Soltani, M. (2013). Comparison effectiveness metacognitive therapy and problem solving therapy on decrease of social anxiety in girl students of Urmia City. Modern psychological research, 7(28), 83-104.

Passer, MW, Smith, R., Holt, N., Bremner,A., Sutherland, E. \& Vliek, M. (2009). McGrath Hill Higher Education; UK: McGrathHill companies Inc.

Rangdust, S. H., \&Eyvazi, P. (2014). The relationship between emotional intelligence of teachers and high school students creative thinking. Research in curriculum planning, 2 (9), 113-125

Shaghaghi, F., \& RezaeiKargar, F. (2010). The effect of creative and critical thinking skills teaching on psychological well-being of adolescents. Journal of psychological researches, 2(5), 49-66. 


\section{Analysis of the Relationship between Social Phobia and Creative Thinking and Problem Solving of the Teenage Girls}

Shakeri, M., Abdollazadeh, B., Mohammadkhani, S., \&Nori, R. (2014). Comparison between personality factors, problem-solving styles and the amount of experienced stress among drug-dependent individuals and normal individuals. Journal of North Khorasan University of Medical Sciences, 6 (2), 329-337.

Sternberg, R. J., \& Grigorenko, E. L. (2000). Teaching for successful intelligence. Arlington Heights, I.L: skylight.

Wells, A. (2004). Cognitive therapy for social phobia. Handbook of brief cognitive behavior therapy, 141.

Zare, H., \& Baradaran, M. (2015). Standardization parker's problem solving inventory (PPSI) among college students of Guilan PNU. Journal of research in learning and virtual school, 2(5), 18-26.

How to cite this article: Afshar A (2017), Analysis of the Relationship between Social Phobia and Creative Thinking and Problem Solving of the Teenage Girls, International Journal of Indian Psychology, Volume 4, Issue 2, No. 89, ISSN:2348-5396 (e), ISSN:2349-3429 (p), DIP:18.01.085/20170402, ISBN:978-1-365-74162-3 